\title{
Pathology outreach in schools/hospitals
}

\section{Opinion}

Targeting a group of school students especially class $11^{\text {th }} \& 12^{\text {th }}$ with Biology as the major subject $\&$ making them aware of the importance of PATHOLOGY as the underlying basis of a disease process \& the molecular \& genetic basis of diseases-infective, metabolic, neoplastic. Poster Presentations, Group Discussions, Debates \& Science Projects can be included in the teaching curricula of senior science students to increase their interest, knowledge \& awareness about the subject \& its involvement in day to day life.

School Teachers can also be trained for the same to some extent. However, it is more response- orienting to use bright, young, eager, $\&$ unformed minds.

Simplifying medical terminology would be the responsibility of medical personnel, for which a junior faculty member/ specialist registrar could be posted to visit the schools on a weekly/rotational basis, especially from the catchment area of a medical school/ university hospital located near the senior secondary schools.

Pathology is a major subject in the medical school (mainly third year) but required throughout the four years of undergraduate training $\&$ well into the acceptance of the students into the postgraduate training programme.

Similar poster presentations, debates, group discussions can be held for medical undergraduates which will increase their interest in the subject \& the possibility of their accepting it as a postgraduate discipline.

Weekly "PATHOLOGY CLINICS" can be held in the hospitals for improving patient awareness \& each week a lecture can be held (in layman terminology) on various interesting, recent \& thought provoking topics. Again, Faculty members / Specialist registrars can be appointed to speak at the weekly lectures.

The Following Topics should be discussed to improve patient awareness, education in schools \& hospitals-

i. Basic Definitions-Cellular Adaptation, Atrophy, Hypertrophy, Metaplasia, Cellular Injury-Reversible \& Irreversible, Apoptosis etc.

ii. Causes \& Mechanisms of Cell Injury-Physical, Chemical, Immunologic, Infectious, Genetic, Nutritional, Free Radical Injury etc.

iii. Cellular ageing- mechanisms \& changes.

iv. Cell Cycle- Cellular growth factors, Growth inhibition \& Regulation etc.

v. Brief Overview of Inflammation \& Repair, the Acute Inflammatory Response, Summary of Chemical Mediators
Volume 2 Issue I - 2016

\author{
Anubha Bajaj \\ Consultant Histopathologist at A.B.Diagnostics, India
}

Correspondence: Anubha Bajaji, Consultant Histopathologist at A B Diagnostics, New Delhi, India, Email anubha.bajaj@gmail.com

Received: February 03, 2016 | Published: February 10, 2016

of Acute Inflammation (names only), mechanisms of wound healing.

vi. Genetic Disorders-Single Gene Disorders, their Transmission Patterns, molecular basis of single gene disorders etc, Disorders with Multifactorial Inheritance, Cytogenetic Disorders. Techniques of molecular diagnosis - Direct/Indirect techniques of Diagnosis, Gene Tracking, \& Recombinant DNA techniques.

vii. Neoplasia- Nomenclature \& Characteristics of Benign/ Malignant Neoplasms, Environmental factors in Neoplasia, molecular basis of cancer, Carcinogenic agents, Viral Carcinogenesis, Gene therapy of tumors, Clinical features of tumors, Laboratory Diagnosis of Cancer.

viii. Infectious Diseases: Categories of Infectious Agents- Viruses (especially newer agents- HIV, HCV, HBV), Bacteria, Bacteriophages, Plasmids, Fungal, Protozoal, Helminthes, STD's, Infections of childhood \& adolescence- measles , mumps, EBV, Varicella Zoster, Whooping Cough etc.

ix. Environmental \& Nutritional Diseases- Tobacco Smoking, Adverse Drug Reactions, Oral Contraceptives, Alcohol, Environmental \& Occupational Carcinogens, Street Drugs etc. Injuries related to changes of temperature, Whole body Radiation, Acute Radiation Injury, Obesity, Diet \& Cancer.

x. Basics of Microbiology: General Bacteriology, History, Bacterial cell, morphology, sterilization, Immunity, AntigenAntibody Reactions, Bacteriological exam of water/milk, Mycoses \& pathogenetic fungi.

Since to promote the subject of Pathology \& to educate the public, school students \& patients, an exhaustive effort is required, as enlisted above, any kind of support $\&$ funding for the cause would be welcome.

\section{Acknowledgements}

None.

\section{Conflict of interest}

Author declares that there is no conflict of interest. 